\title{
Characteristics Indicative of Tuberculosis/HIV Coinfection in a High-Burden Setting: Lessons from 13,802 Incident Tuberculosis Cases in Harare, Zimbabwe
}

\author{
Richard J. Martino, ${ }^{1}$ Joconiah Chirenda, ${ }^{2}$ Hilda A. Mujuru, ${ }^{3}$ Wen Ye, ${ }^{4}$ and Zhenhua Yang ${ }^{1 *}$ \\ ${ }^{1}$ Department of Epidemiology, School of Public Health, University of Michigan, Ann Arbor, Michigan; ${ }^{2}$ Department of Community Medicine, \\ College of Health Sciences, University of Zimbabwe, Harare, Zimbabwe; ${ }^{3}$ Department of Pediatrics, College of Health Sciences, University of \\ Zimbabwe, Harare, Zimbabwe; ${ }^{4}$ Department of Biostatistics, School of Public Health, University of Michigan, Ann Arbor, Michigan
}

\begin{abstract}
Country-specific interventions targeting high-risk groups are necessary for a global reduction in Tuberculosis (TB)/HIV burden. We analyzed the data of 13,802 TB cases diagnosed in Harare, Zimbabwe, during 2013-2017. Pearson's chi-square tests and multivariate logistic regression models were used to identify patient characteristics significantly associated with TB/HIV coinfection. Of the 13,802 TB cases analyzed, 9,725 (70.5\%) were HIV positive. A significantly higher odds of having TB/HIV coinfection diagnosis was found among females, patients aged 25-64 years, previously treated cases, and acid-fast bacillus sputum smear-negative cases. Compared with nondisseminated pulmonary TB, miliary TB (adjusted odds ratio [aOR]: 1.469 , 95\% Cl: $1.071,2.015)$ and TB meningitis (aOR: $1.715,95 \% \mathrm{Cl}$ : $1.074,2.736)$ both had a significantly higher odds for TB/HIV coinfection, whereas pleural TB (aOR $0.420,95 \% \mathrm{Cl}: 0.354$, 0.497 ) and all other extrapulmonary TB (EPTB) (aOR: $0.606,95 \% \mathrm{Cl}: 0.5160 .712$ ) were significantly less likely to have TB/HIV coinfection. The risk for TB/HIV coinfection varied significantly by patients' sociodemographic and clinical characteristics in Harare. Our finding that different forms of EPTB have different relationships with HIV coinfection has extended the knowledge base about clinical markers for TB/HIV coinfection which can lead to a greater public health impact on eliminating TB/HIV infection.
\end{abstract}

\section{INTRODUCTION}

Tuberculosis (TB) continues to be a major global burden as one of the leading causes of death for communicable diseases, with 1.5 million deaths in 2018. ${ }^{1}$ Because TB is the leading cause of death for people living with HIV, HIV and TB coinfection must be addressed if we are to meet the Sustainable Development Goal of the United Nations to eliminate TB and AIDS by $2030 .{ }^{1}$ The need for country-specific TB interventions has been identified as a key strategy in ending TB. ${ }^{2}$

Zimbabwe, the study site, carries a high burden of TB and TB/ HIV coinfection and is currently one of the WHO-defined 30 highburden countries for TB and TB/HIV coinfection. ${ }^{1}$ In 2018, the TB incidence rate for Zimbabwe was estimated to be 210 cases per 100,000 and the TB/HIV coinfection rate was 130 cases per $100,000 .^{1}$ A better understanding of the characteristics of cases with TB/HIV coinfection will allow for an improvement in the identification of coinfection, thereby leading to the timely treatment of both diseases and prevention of the spread of disease.

The presentation of TB disease in people living with HIV can make diagnosis difficult for clinicians, with some TB diagnosis occurring postmortem. ${ }^{3,4}$ Previous studies have contributed fundamental knowledge to TB prevention strategies by identifying key TB characteristics for HIV-seropositive and -seronegative patients in some populations. ${ }^{5-8}$ Such knowledge is important, as failure to receive antiretroviral therapy for HIV infection in TB patients is known to be a risk factor for poor health outcomes of TB/HIV-coinfected patients. ${ }^{9}$ With a better understanding of how TB disease disseminates throughout the body of people living with and without HIV, clinicians are able to make timely, accurate diagnosis of the disease. A previous study conducted in Zimbabwe characterized pediatric TB cases with and without HIV infection during 2011-2012. However, the

\footnotetext{
* Address correspondence to Zhenhua Yang, Department of Epidemiology, School of Public Health, University of Michigan, 1415 Washington Heights, Ann Arbor, Ml 48109. E-mail: zhenhua@
} umich.edu characteristics of TB/HIV coinfection among adults remain largely unknown. ${ }^{6}$ This cross-sectional study is the first study to include patients of all ages in the characterization of TB cases with and without HIV infection in Zimbabwe and supports the call for country-specific interventions. ${ }^{1,2}$

\section{METHODS}

Study population and data collection. The study sample included 13,802 (91.1\%) incident TB cases of 15,151 total cases that were diagnosed in Harare, Zimbabwe, and registered in the National TB Registry (NTBR) from 2013 to 2017. Of the 1,349 (9.8\%) cases excluded, 1,298 cases were excluded because of unknown HIV results and 51 cases were excluded for not being incident cases. The study cases were diagnosed at Beatrice Road Infectious Diseases Hospital (BRIDH), Wilkins Infectious Diseases Hospital (WIDH), and several other referral clinics in Harare. Tuberculosis cases were diagnosed, in principle, following the $\mathrm{WHO}$ recommended algorithms. ${ }^{10,11}$ However, although there had been an increase in the use of Xpert MTB/RIF over time in Zimbabwe, the routine diagnosis of TB sometimes was carried out using only direct sputum smear microscopy during the study period. GeneXpert MTB/RIF technology was only used for high-risk drugresistant TB. Patients negative for two acid-fast bacilli sputum smear (AFBSS) tests and those with signs and symptoms suggestive of TB were referred to the medical officer for chest $\mathrm{X}$-ray and clinical diagnosis of TB as per the guidelines of the WHO. ${ }^{10,12}$

To characterize TB cases with and without HIV coinfection, we retrieved data on the study patients' demographic and clinical characteristics as well as on where the TB diagnosis was made, from the NTBR. The demographic data captured included gender and age. The clinical characteristics included TB treatment history, AFBSS result, site of disease, and HIV status determined routinely at the diagnosis of TB. The data set was deidentified before the data analysis. The data collection protocol was approved by both the University of Michigan Health Science and Behavior Science Institutional Review Board (HSBS-IRB) and the Ethical Committee of the University of Zimbabwe. The 
study was determined unregulated by the University of Michigan HSBS-IRB, given it used de-identified patient data.

Patient classification. To compare the characteristics of patients with and without HIV coinfection, we grouped the study patients by HIV status and then subgrouped the HIV-positive and -negative patients by demographics and other clinical characteristics. The study patients were classified as new or previously treated patients based on the WHO definitions. ${ }^{11}$

To more thoroughly explore clinical characteristics associated with TB/HIV coinfection, the study patients were also classified based on the site of their disease, using three different classification systems. The first classification system (designated disease classification 1) grouped the study patients into two categories: pulmonary TB (PTB) and extrapulmonary TB (EPTB), following the classification methodology that was commonly used by the WHO in its annual global TB surveillance report. ${ }^{11}$ In this classification system, PTB also included miliary TB cases and EPTB included all cases whose disease occurred outside their lungs including pleural TB. The second classification system (designated disease classification 2), which grouped the patients into three categories: 1) thoracic TB (TTB), 2) extrathoracic TB (ETTB), and 3) miliary TB, was explored to search for better clinical markers for TB/HIV coinfection diagnosis, given that the classification system described earlier can potentially misclassify miliary TB occurring outside the lung as PTB, skewing the association in question, especially in a high-TB/HIV coinfection population. For a similar purpose, we explored the usefulness of a third classification system (designated disease classification 3) in the identification of patient characteristics associated with TB/HIV coinfection. This third classification system classified the patients into five categories, including nondisseminated pulmonaryTB (NDPTB), miliary TB, pleural TB, TB meningitis, and all other forms of EPTB.

Data analysis. To identify patient characteristics associated with a TB/HIV coinfection diagnosis, we first compared the frequency distributions of patient demographic and clinical characteristics between patient groups with and without HIV infection and tested the association of these characteristics with HIV status using Pearson's chi-square test and bivariate logistic regression. Percent difference between the HIV-positive $(\mathrm{HIV+})$ group and the HIV-negative (HIV-) group and its $95 \% \mathrm{Cl}$ for each characteristic were calculated. To control for potential confounders, we next performed three multivariate logistic regressions to obtain adjusted odds ratios (aORs), based on each of the three classification systems described earlier. For the three models, model fit was assessed using the Pearson goodness-of-fit test, and the variance inflation factor for each model parameter was calculated to check for multicollinearity. Considering the possibility that the covariate effect on HIV infection might differ between patients with and without previous TB treatment, we also performed similar analysis using three multivariate logistic regression models stratified by treatment history (new versus previously treated TB cases). In addition, to examine the potential bias of the study sample, we compared the distribution of patient characteristics between the 13,802 study cases and the 1,349 cases excluded from the study sample using Pearson's chi-square test.

\section{RESULTS}

Characteristics of study patient. Of the 13,802 cases analyzed, 8,724 (63.2\%) came from BRIDH. Male patients were the majority, 8,106 (58.7\%)(Table 1). Patient age ranged from 0 to 97

years, with the median age being 35 (interquartile range: 16) years. There were $12,653(91.7 \%)$ new TB cases. The HIVseropositive cases accounted for $70.5 \%(9,725 / 13,802)$ of the study sample. Of the 12,872 cases with AFBSS test results and known ages, 0-14, 25-64, and 65+ age-groups had a greater percentage of AFBSS-negative results than AFBSS-positive results (Figure 1). A majority $(82.8 \%)$ of cases had nondisseminated TB, whereas the remaining cases had miliary TB (2.6\%), pleural TB (6.0\%), TB meningitis (1.3\%), and all other EPTB (7.4\%) (Table 1). The most common form of EPTB was pleural TB, with 40.7\% (823/2024) (Figure 2). Data on concurrent pulmonary and extra pulmonary involvement were not available.

Characteristics associated with TB/HIV diagnosis. Pearson's chi-square tests were conducted, and unadjusted odds ratios and $P$-values were reported to identify the differences between HIV-seropositive and HIV-seronegative groups (Table 2). Using three multivariate logistic regression models by three different disease classification systems described earlier,

TABLE 1

Demographic and clinical characteristics of 13,802 tuberculosis (TB) cases diagnosed in Harare, Zimbabwe, during 2013-2017

\begin{tabular}{|c|c|c|}
\hline Variable & Number of cases & Percentage of cases \\
\hline \multicolumn{3}{|l|}{ Age-group (years) } \\
\hline $0-14$ & 1,191 & 8.6 \\
\hline $15-24$ & 1,473 & 10.7 \\
\hline $25-64$ & 10,621 & 77.0 \\
\hline $65+$ & 501 & 3.6 \\
\hline \multicolumn{3}{|l|}{ Gender } \\
\hline Male & 8,106 & 58.7 \\
\hline Female & 5,696 & 41.3 \\
\hline \multicolumn{3}{|l|}{ Treatment history } \\
\hline New & 12,653 & 91.7 \\
\hline Previously treated & 1,149 & 8.3 \\
\hline \multicolumn{3}{|l|}{ AFBSS result $†$} \\
\hline Negative & 7,504 & 58.2 \\
\hline Positive & 5,384 & 41.8 \\
\hline \multicolumn{3}{|l|}{ HIV status } \\
\hline Negative & 4,077 & 29.5 \\
\hline Positive & 9,725 & 70.5 \\
\hline \multicolumn{3}{|l|}{ Medical center $\ddagger$} \\
\hline BRIDH & 8,724 & 63.2 \\
\hline WIDH & 3,000 & 21.7 \\
\hline Other clinics & 2,085 & 15.1 \\
\hline \multicolumn{3}{|l|}{ Disease classification $1 \S$} \\
\hline PTB with miliary TB & 11,778 & 85.3 \\
\hline EPTB & 2,024 & 14.7 \\
\hline \multicolumn{3}{|l|}{ Disease classification 2\| } \\
\hline TTB & 12,247 & 88.7 \\
\hline ETTB & 1,201 & 8.7 \\
\hline Miliary TB & 354 & 2.6 \\
\hline \multicolumn{3}{|l|}{ Disease classification 3} \\
\hline NDPTB & 11,424 & 82.8 \\
\hline Miliary TB & 354 & 2.6 \\
\hline Pleural TB & 823 & 6.0 \\
\hline TB meningitis & 177 & 1.3 \\
\hline All other EPTB & 1,024 & 7.4 \\
\hline \multicolumn{3}{|c|}{ 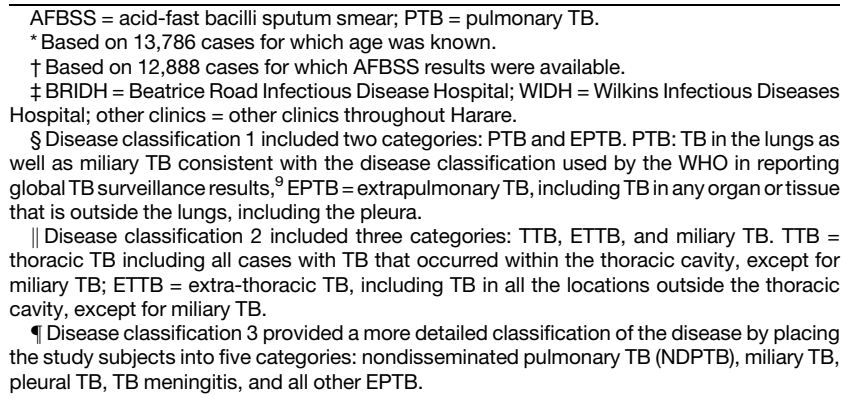 } \\
\hline
\end{tabular}




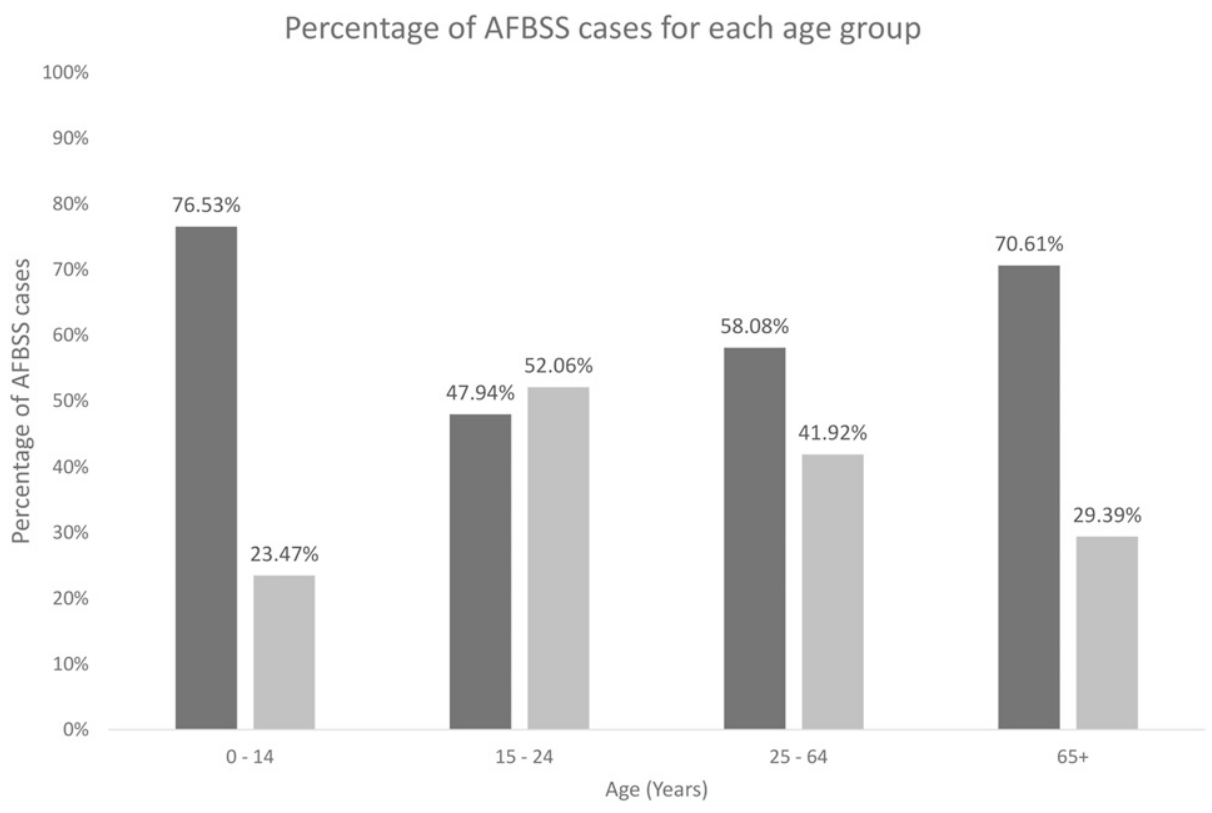

FIGURE 1. Frequency distribution of acid-fast bacillus sputum smear (AFBSS) results among different age-groups of TB cases diagnosed in Harare, Zimbabwe, during 2013-2017 ( $N=12,872)$. Black bars represent AFBSS-negative cases; gray bars represent AFBSS-positive cases.

we identified several patient characteristics that are significantly associated with TB/HIV coinfection (Table 3). More specifically, all the three models consistently revealed a significantly increased likelihood for having TB/HIV coinfection among females compared with males, people in the 25-64 age-group compared with people in the age-groups of $0-14$ and 15-24 years, patients having a previous TB treatment history compared with the new patients, AFBSS-negative patients compared with AFBSSpositive ones, and patients diagnosed at BRIDH compared with those diagnosed at WIDH.
The disease classification 3 model indicated that patients with miliary TB (aOR: $1.469,95 \% \mathrm{Cl}: 1.071,2.015)$ and TB meningitis (aOR: $1.715,95 \% \mathrm{Cl}: 1.074,2.736$ ) were significantly more likely to have TB/HIV coinfection than those with NDPTB, whereas patients with pleural TB (aOR: $0.420,95 \% \mathrm{Cl}: 0.354,0.497)$ and all other EPTB (aOR: $0.606,95 \% \mathrm{Cl}: 0.516,0.712$ ) were found to be significantly less likely to have TB/HIV coinfection. In addition, the disease classification 2 model indicated that compared with nondisseminated TTB, patients with miliary TB were significantly more likely to have TB/HIV coinfection (aOR: $1.647,95 \% \mathrm{Cl}$ :

\section{PERCENTAGE OF EPTB DISEASE}

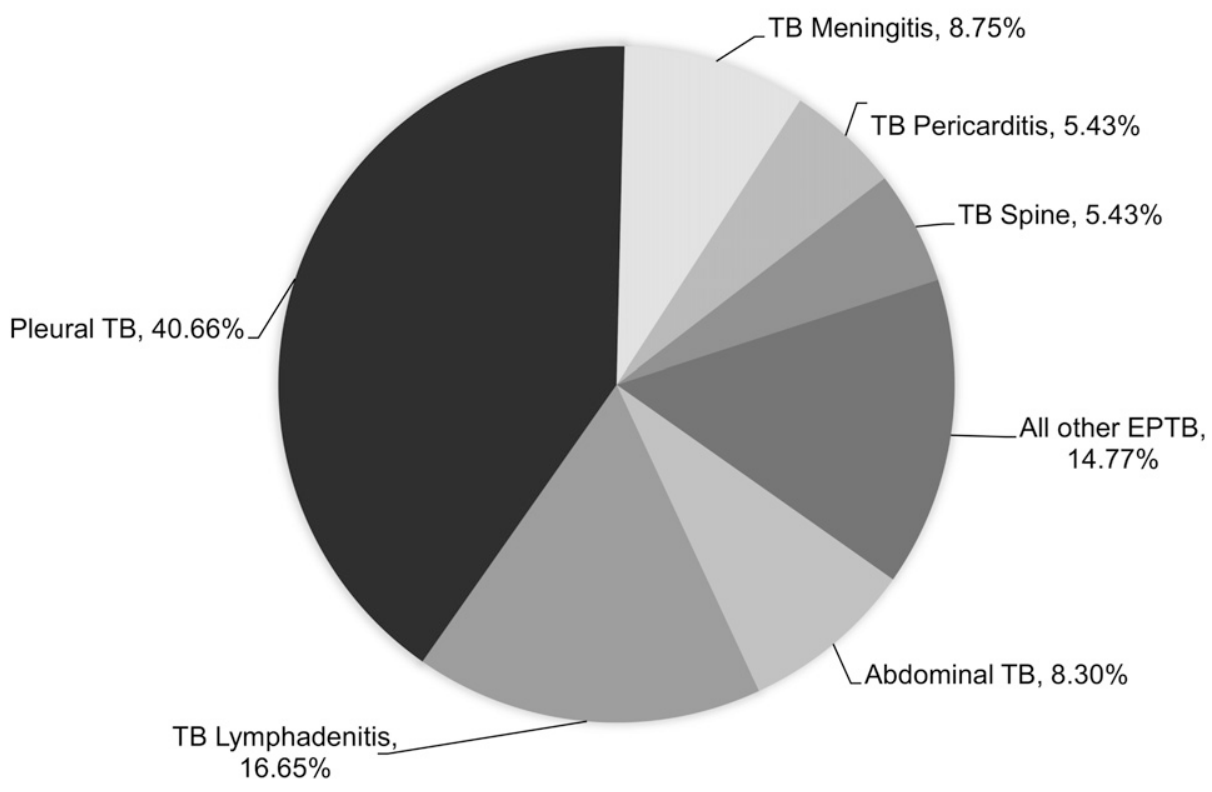

FIGURE 2. Frequency distribution of different forms of extrapulmonary TB (EPTB) among 2,024 EPTB cases diagnosed in Harare, Zimbabwe, during 2013-2017. 
TABLE 2

Comparison of demographic and clinical characteristics between HIV-positive and HIV-negative TB cases who were diagnosed in Harare, Zimbabwe, during 2013-2017

\begin{tabular}{|c|c|c|c|c|c|c|}
\hline & \multicolumn{2}{|c|}{ HIV+ } & \multicolumn{2}{|c|}{ HIV- } & \multirow[b]{3}{*}{ Unadjusted OR $(95 \%$ Cl) } & \multirow[b]{3}{*}{$P$-value§ } \\
\hline & \multicolumn{2}{|c|}{$(N=9,725)$} & \multicolumn{2}{|c|}{$(N=4,077)$} & & \\
\hline & $N$ & $\%^{*}$ & N & $\%^{*}$ & & \\
\hline \multicolumn{7}{|l|}{ Age-group (years) \| } \\
\hline $15-24$ & 791 & 8.1 & 682 & 16.8 & $1.389(1.191,1.619)$ & $<0.0001$ \\
\hline $25-64$ & 8,213 & 84.5 & 2,408 & 59.2 & $4.084(3.612,4.617)$ & $<0.0001$ \\
\hline $65+$ & 169 & 1.7 & 332 & 8.2 & $0.610(0.490,0.758)$ & $<0.0001$ \\
\hline $0-14$ & 542 & 5.6 & 649 & 15.9 & Ref & \\
\hline \multicolumn{7}{|l|}{ Gender } \\
\hline Female & 4,080 & 42 & 1,616 & 39.6 & $1.101(1.022,1.186)$ & 0.0117 \\
\hline Male & 5,645 & 58.1 & 2,461 & 60.4 & Ref & \\
\hline \multicolumn{7}{|l|}{ Treatment history } \\
\hline Previously treated & 942 & 9.7 & 207 & 5.1 & $2.005(1.717,2.342)$ & $<.0001$ \\
\hline New & 8,783 & 90.3 & 3,870 & 94.9 & Ref & \\
\hline \multicolumn{7}{|l|}{ AFBSS resultq } \\
\hline Positive & 3,504 & 37.8 & 1880 & 52.1 & $0.558(0.516,0.603)$ & $<0.0001$ \\
\hline Negative & 5,776 & 62.2 & 1728 & 47.9 & Ref & - \\
\hline \multicolumn{7}{|l|}{ Medical center\# } \\
\hline WIDH & 2,084 & 21.4 & 916 & 22.5 & $0.878(0.802,0.962)$ & 0.0051 \\
\hline Other clinics & 1,354 & 13.9 & 731 & 17.9 & $0.711(0.643,0.787)$ & $<0.0001$ \\
\hline BRIDH & 6,294 & 64.7 & 2,430 & 59.6 & Ref & - \\
\hline \multicolumn{7}{|c|}{ Disease classification $1^{\star \star}$} \\
\hline EPTB & 1,385 & 14.2 & 639 & 15.7 & $0.893(0.807,0.989)$ & 0.0301 \\
\hline PTB with miliary TB & 8,340 & 85.8 & 3,438 & 84.3 & Ref & - \\
\hline \multicolumn{7}{|c|}{ Disease classification $2 \nmid \dagger$} \\
\hline ETTB & 862 & 8.9 & 339 & 8.3 & $1.094(0.959,1.248)$ & 0.1806 \\
\hline Miliary TB & 300 & 3.1 & 54 & 1.3 & $2.39(1.784,3.201)$ & $<0.0001$ \\
\hline TाB & 8,563 & 88.1 & 3,684 & 90.4 & Ref & - \\
\hline \multicolumn{7}{|c|}{ Disease classification $3 \neq \ddagger$} \\
\hline Miliary TB & 300 & 3.1 & 54 & 1.3 & $2.338(1.745,3.133)$ & $<0.0001$ \\
\hline TB meningitis & 150 & 1.5 & 27 & 0.7 & $2.338(1.549,3.529)$ & $<0.0001$ \\
\hline Pleural TB & 523 & 5.4 & 300 & 7.4 & $0.734(0.633,0.850)$ & $<0.0001$ \\
\hline All other EPTB & 712 & 7.3 & 312 & 7.7 & $0.961(0.836,1.104)$ & 0.5699 \\
\hline NDPTB & 8,040 & 82.7 & 3,384 & 83 & Ref & - \\
\hline \multicolumn{7}{|c|}{ 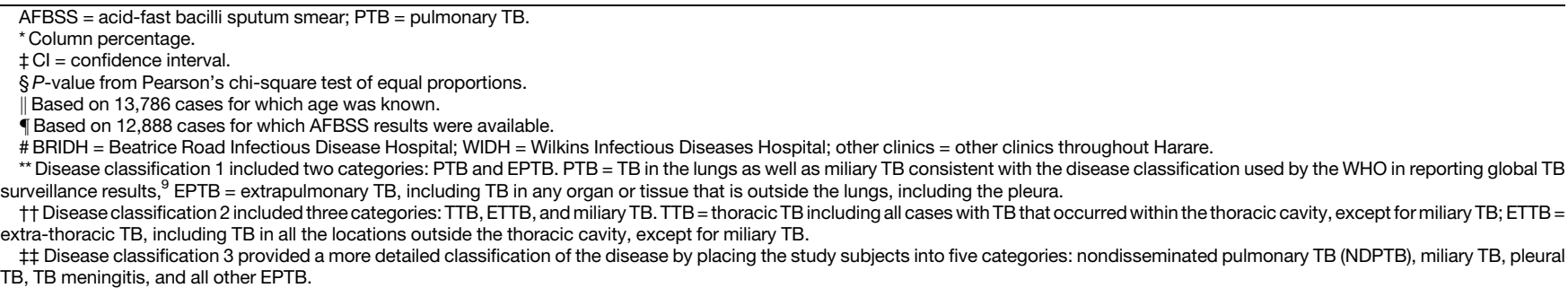 } \\
\hline
\end{tabular}

1.202, 2.255); by contrast, patients with ETTB in addition to pleural TB, but not miliary TB, were less likely to have TB/HIV coinfection. With disease classification 1, PTB with miliary TB was found to be associated with a higher risk of TB/HIV coinfection than EPTB. The associations described earlier were similar to those found in the stratified analyses for the new (incident) case group that accounted for $92 \%$ of the study sample (Supplemental Table 1). However, the results of the stratified analyses for the previously treated group (Supplemental Table 2) showed that because of the low frequency of the previously treated cases, especially in the miliary TB subcategory, the odds ratios could not be reliably estimated and that there might not be enough statistical power to study the differences between different disease types in the previously treated group.

\section{DISCUSSION}

We explored major demographic and clinical characteristics that were significantly, differentially distributed among HIV- positive and -negative TB cases in Harare, Zimbabwe, to identify patient characteristics associated with TB/HIV coinfection. As the first study to include patients of all ages in the characterization of TB cases with and without HIV infection in Zimbabwe, our study found that approximately $70 \%$ of the study patients were coinfected with HIV, which is similar to the WHO report that $72 \%$ of TB cases in Africa were HIV coinfected. ${ }^{13}$ It is concerning to have such a high frequency of HIV coinfection in any population, given that $\mathrm{HIV}$ is the leading cause of death for people with TB disease. ${ }^{13}$

All three models (Table 3) consistently showed a significantly increased odds for having TB/HIV coinfection for people aged 25-64 years compared with the 0-14 and 15-24 age-groups. In 2012 , the 25-64 age-group accounted for $42 \%$ of the general population of Harare, but this age-group accounted for $77 \%$ of TB cases in our study sample. ${ }^{14}$ Tuberculosis has disproportionally affected the most productive age-group of the population in Harare, Zimbabwe. This can have significant implications for families and society. ${ }^{15,16}$ Although TB treatment is free in Zimbabwe, the total cost related to seeking TB treatment, such 
TABLE 3

Results of multivariate logistic regression analyses to identify patient characteristics associated with having TB/HIV coinfection diagnosis using three different models ${ }^{*}$ based on three different disease classifications $(N=12,827) \dagger$

\begin{tabular}{|c|c|c|c|c|c|c|}
\hline & \multicolumn{2}{|l|}{ Model 1} & \multicolumn{2}{|l|}{ Model 2} & \multicolumn{2}{|l|}{ Model 3} \\
\hline & Adjusted OR (95\% Cl) & $P$-value & Adjusted OR (95\% Cl) & $P$-value & Adjusted OR $(95 \% \mathrm{Cl})$ & $P$-value \\
\hline \multicolumn{7}{|l|}{ Age-group (years) } \\
\hline $15-24$ & $1.102(0.903,1.345)$ & 0.3379 & $1.114(0.913,1.359)$ & 0.2868 & $1.173(0.959,1.433)$ & 0.1197 \\
\hline $25-64$ & $3.177(2.669,3.782)$ & $<0.0001$ & $3.178(2.670,3.783)$ & $<0.0001$ & $3.384(2.837,4.036)$ & $<0.0001$ \\
\hline $65+$ & $0.402(0.312,0.519)$ & $<0.0001$ & $0.409(0.317,0.526)$ & $<0.0001$ & $0.435(0.337,0.562)$ & $<0.0001$ \\
\hline $0-14$ & Ref & - & Ref & - & Ref & - \\
\hline \multicolumn{7}{|l|}{ Gender } \\
\hline Female & $1.245(1.146,1.354)$ & $<0.0001$ & $1.240(1.141,1.348)$ & $<0.0001$ & $1.243(1.144,1.352)$ & $<0.0001$ \\
\hline Male & Ref & - & Ref & - & Ref & - \\
\hline \multicolumn{7}{|l|}{ Treatment history } \\
\hline Previously treated & $1.733(1.471,2.043)$ & $<0.0001$ & $1.783(1.514,2.100)$ & $<0.0001$ & $1.729(1.467,2.038)$ & $<0.0001$ \\
\hline New & Ref & - & Ref & - & Ref & - \\
\hline \multicolumn{7}{|l|}{ AFBSS result $\ddagger$} \\
\hline Positive & $0.458(0.416,0.505)$ & $<0.0001$ & $0.526(0.479,0.578)$ & $<0.0001$ & $0.466(0.422,0.513)$ & $<0.0001$ \\
\hline Negative & Ref & - & Ref & - & Ref & - \\
\hline \multicolumn{7}{|l|}{ Medical center§ } \\
\hline WIDH & $0.805(0.729,0.890)$ & $<0.0001$ & $0.825(0.747,0.912)$ & 0.0002 & $0.801(0.724,0.886)$ & $<0.0001$ \\
\hline Other clinics & $0.823(0.732,0.925)$ & 0.0011 & $0.834(0.742,0.937)$ & 0.0023 & $0.819(0.729,0.922)$ & 0.0009 \\
\hline BRIDH & Ref & - & Ref & - & Ref & - \\
\hline \multicolumn{7}{|l|}{ Disease classification 1} \\
\hline EPTB & $0.547(0.484,0.618)$ & $<0.0001$ & - & - & - & - \\
\hline PTB with miliary TB & Ref & - & - & - & - & - \\
\hline \multicolumn{7}{|l|}{ Disease classification 2} \\
\hline ETTB & - & - & $0.773(0.665,0.900)$ & 0.0009 & - & - \\
\hline Miliary TB & - & - & $1.647(1.202,2.255)$ & 0.0019 & - & - \\
\hline ТTВ & - & - & Ref & - & - & - \\
\hline \multicolumn{7}{|l|}{ Disease classification 3} \\
\hline Miliary TB & - & - & - & - & $1.469(1.071,2.015)$ & 0.0171 \\
\hline TB meningitis & - & - & - & - & $1.715(1.074,2.736)$ & 0.0237 \\
\hline Pleural TB & - & - & - & - & $0.420(0.354,0.497)$ & $<0.0001$ \\
\hline All other EPTB & - & - & - & - & $0.606(0.516,0.712)$ & $<0.0001$ \\
\hline NDPTB & - & - & - & - & Ref & - \\
\hline
\end{tabular}

AFBS = acid-fast bacilli sputum smear; PTB = pu

${ }^{\star}$ All the three multivariate regression models included basic demographic variables and all the clinical variables available to this study, except for the disease classification variables that were unique to each model. Model 1 was based on disease classification 1 that included two categories: PTB and EPTB. PTB = TB in the lungs as well as miliary TB consistent with the disease classification used by the WHO in reporting global TB surveillance results; EPTB = extrapulmonary TB, including TB in any organ or tissue that is outside the lungs, including the pleura. Model 2 was based on disease classification 2 that included three categories: TTB, ETTB, and miliary TB. TTB = thoracic TB, including all cases with TB that occurred within the thoracic cavity, except for miliary TB; ETTB = extra-thoracic TB, including TB in all the locations outside the thoracic cavity, except for miliary TB. Model 3 was based on disease classification 3 that provided a more detailed classification of the disease by placing the study subjects into five categories: nondisseminated pulmonary TB (NDPTB), miliary TB, pleural TB, TB meningitis, and all other EPTB.

† Based on the 12,872 observations with complete data for all variables analyzed.

†AFBSS (acid-fast bacilli sputum smear) result.

§BRIDH = Beatrice Road Infectious Disease Hospital; WIDH = Wilkins Infectious Diseases Hospital; other clinics = other clinics throughout Harare.

as transportation and food, for a patient can be $58 \%$ of their reported annual income, which may affect willingness to seek timely treatment. ${ }^{16}$ Untreated cases of the most active, productive group in the society can contribute to the transmission of TB in the population, negatively impacting the TB epidemic in Harare, Zimbabwe. An elevated risk of TB/HIV coinfection in children aged 5 years and older was also reported by an earlier study conducted in Harare, Zimbabwe. ${ }^{6}$ This unchanged risk raises a concern about the lack of progress in reducing TB/HIV coinfection in older children especially because older children in Harare have a high burden of undiagnosed HIV. ${ }^{17,18}$ Age-specific public health interventions for TB/HIV prevention are necessary to limit future TB/HIV coinfection.

For gender, we found the male-to-female (M:F) ratio of TB cases to be approximately $1.42: 1$, which is consistent with the WHO Zimbabwe national TB profile but differs greatly from the 0.93:1 (M:F) of the Harare population in 2012. ${ }^{1,19}$ Higher M:F for TB cases than M:F for the general Harare population may indicate that males were disproportionally affected by TB in the study population. The gender difference in TB incidence has been found to be about 2:1 in previous studies conducted in Nigeria, ${ }^{20}$ San Francisco, the United States, ${ }^{21}$ whereas the WHO reported the global M:F of TB as 1:7 for $2018 .^{1}$
From the three multivariate logistic regression models, we consistently found that females had a significantly elevated odds ratio for TB/HIV coinfection compared with males. Previous studies have reported gender disparities in other countries $^{22-25}$; an increased risk for females was found in Nigeria ${ }^{20}$ and Ghana. $^{26}$ However, this was the first study to report the elevated risk for women in Harare, Zimbabwe. It was particularly intriguing that the female gender and TB/HIV coinfection association was neither found in a previous study conducted in the pediatric TB population in Harare ${ }^{6}$ nor in an early study conducted in a different region of Zimbabwe. ${ }^{27}$ Further research on the gender disparities of TB/HIV coinfection in Harare is needed to better understand why women are at an increased risk of coinfection compared with men, although men carry the largest burden of TB disease.

Cases with a previous history of TB treatment made up a small percent (approximately 9\%) of TB cases in the study sample but were found to be associated with having TB/HIV coinfection diagnosis in the current study, which is consistent with previous studies. $^{28,29}$ The driving forces for the association may be the high risk of TB disease progression for people living with HIV infection $^{30}$ and the risk of TB drug resistance for previously 
Medicine, College of Health Sciences, University of Zimbabwe, Harare, Zimbabwe, E-mail: joconiahc@gmail.com. Hilda A. Mujuru, Department of Pediatrics, College of Health Sciences, University of Zimbabwe, Harare, Zimbabwe, E-mail: drhamujuru@gmail.com. Wen $\mathrm{Ye}$, Department of Biostatistics, School of Public Health, University of Michigan, Ann Arbor, MI, E-mail: wye@umich.edu.

\section{REFERENCES}

1. World Health Organization, 2019. Global Tuberculosis Report 2019. Geneva, Switzerland: World Health Organization.

2. Houben RMGJ et al., 2016. Feasibility of achieving the 2025 WHO global tuberculosis targets in South Africa, China, and India: a combined analysis of 11 mathematical models. Lancet Glob Health 4: e806-e815.

3. Bobrowitz ID, 1982. Active tuberculosis undiagnosed until autopsy. Am J Med 72: 650-658.

4. Gupta RK, Lucas SB, Fielding KL, Lawn SD, 2015. Prevalence of tuberculosis in post-mortem studies of HIV-infected adults and children in resource-limited settings: a systematic review and meta-analysis. AIDS 29: 1987-2002.

5. Campos LC, Rocha MV, Willers DM, Silva DR, 2016. Characteristics of patients with smear-negative pulmonary tuberculosis (TB) in a region with high TB and HIV prevalence. PLoS One 11: 0147933.

6. Earley M, Chirenda J, Highet A, Mujuru HA, Yang Z, 2018. Characterizing pediatric tuberculosis with and without human immunodeficiency virus coinfection in Harare, Zimbabwe. Am J Trop Med Hyg 99: 601-607.

7. Olowe OA, Makanjuola OB, Adekanmi AS, Adefioye OJ, Olowe RA, 2017. Epidemiological characteristics and clinical outcome of HIV-related tuberculosis in a population of TB patients in southwestern Nigeria. Eur J Microbiol Immunol (Bp) 7: 127-132.

8. Wei W, Wei-Sheng Z, Ahan A, Ci Y, Wei-Wen Z, Ming-Qin C, 2016. The characteristics of TB epidemic and TB/HIV co-infection epidemic: a 2007-2013 retrospective study in Urumqi, Xinjiang Province, China. PLoS One 11: e0164947.

9. Ncube R, Takarinda KC, Zishiri C, Boogaard W, Mlilo N, Chiteve C, Siziba N, Trinchán F, Sandy C, 2017. Age-stratified tuberculosis treatment outcomes in Zimbabwe: are we paying attention to the most vulnerable? Public Health Action 7: 212-217.

10. Zimbabwe Ministry of Health \& Child Welfare, 2010. National Guidelines for TB/HIV Co-Management. Available at: https:// www.who.int/hiv/pub/guidelines/zimbabwe.pdf. Accessed February 24, 2019.

11. World Health Organization, 2014. Definitions and Reporting Framework for Tuberculosis - 2013 Revision. Available at: https://apps.who.int/iris/bitstream/handle/10665/79199/ 9789241505345_eng.pdf;jsessionid=EE011416697B413ACC672OF 81EC62402? sequence=1. Accessed February 13, 2019.

12. Zimbabwe Ministry of Health \& Child Welfare, 2017. National Tuberculosis Program-Strategic Plan (2017-2020). Available at: https://depts.washington.edu/edgh/zw/hit/web/project-resources/ TB-NSP.pdf. Accessed February 24, 2019.

13. World Health Organization, 2018. Global Tuberculosis Report 2018. Available at: https://apps.who.int/iris/bitstream/handle/ 10665/274453/9789241565646-eng.pdf. Accessed February 21,2019

14. ZimStat, 2012. Census 2012 Provincial Report Harare. Available at: http://www.zimstat.co.zw/sites/default/files/img/publications/ Population/Harare.pdf. Accessed February 24, 2019.

15. Rajeswari $R$, Balasubramanian $R$, Muniyandi $M$, Geetharamani $S$, Thresa X, Venkatesan P, 1999. Socio-economic impact of tuberculosis on patients and family in India. Int J Tuberc Lung Dis 3: 869-877.

16. Tanimura T, Jaramillo E, Weil D, Raviglione M, Lönnroth K, 2014. Financial burden for tuberculosis patients in low- and middleincome countries: a systematic review. Eur Respir J 43: 1763-1775.

17. Simms V et al., 2017. Community burden of undiagnosed HIV infection among adolescents in Zimbabwe following primary healthcare-based provider-initiated HIV testing and counselling: a cross-sectional survey. PLoS Med 14: e1002360.

18. Ferrand RA, Luethy R, Bwakura F, Mujuru H, Miller RF, Corbett EL, 2007. HIV infection presenting in older children and adolescents: a case series from Harare, Zimbabwe. Clin Infect Dis 44: 874-878.
19. ZimStat, 2012. Zimbabwe Population Census 2012 Women and Men Profile Summary Report. Available at: http://www.zimstat.co. zw/sites/default/files/img/publications/Health/Women_and Men_Summary_Report_2012.pdf. Accessed February 24, 2019.

20. Aliyu G, El-Kamary SS, Abimiku A, Blattner W, Charurat M, 2018. Demography and the dual epidemics of tuberculosis and HIV: analysis of cross-sectional data from sub-Saharan Africa. PLoS One 13: e0191387.

21. Martinez AN, Rhee JT, Small PM, Behr MA, 2000. Sex differences in the epidemiology of tuberculosis in San Francisco. Int $J$ Tuberc Lung Dis 4: 26-31.

22. Austin JF, Dick JM, Zwarenstein M, 2004. Gender disparity amongst TB suspects and new TB patients according to data recorded at the South African institute of medical research laboratory for the Western cape region of South Africa. Int $J$ Tuberc Lung Dis 8: 435-439.

23. Begum V, de Colombani $P$, Das Gupta $S$, Salim AH, Hussain $H$, Pietroni M, Rahman S, Pahan D, Borgdorff MW, 2001. Tuberculosis and patient gender in Bangladesh: sex differences in diagnosis and treatment outcome. Int J Tuberc Lung Dis 5: 604-610.

24. Boeree MJ, Harries AD, Godschalk P, Demast Q, Upindi B, Mwale A, Nyirenda TE, Banerjee A, Salaniponi FML, 2000. Gender differences in relation to sputum submission and smearpositive pulmonary tuberculosis in Malawi. Int $J$ Tuberc Lung Dis 4: 882-884.

25. Long NH, Johansson E, Diwan VK, Winkvist A, 2001. Fear and social isolation as consequences of tuberculosis in Vietnam: a gender analysis. Health Policy 58: 69-81.

26. Osei E, Der J, Owusu R, Kofie P, Axame WK, 2017. The burden of HIV on tuberculosis patients in the Volta region of Ghana from 2012 to 2015: implication for tuberculosis control. BMC Infect Dis 17: 504.

27. Takarinda KC, Harries AD, Srinath S, Mutasa-Apollo T, Sandy C, Mugurungi $O, 2012$. Treatment outcomes of adult patients with recurrent tuberculosis in relation to HIV status in Zimbabwe: a retrospective record review. BMC Public Health 12: 124.

28. Crampin AC, Mwaungulu JN, Mwaungulu FD, Mwafulirwa DT, Munthali K, Floyd S, Fine PE, Glynn JR, 2010. Recurrent TB: relapse or reinfection? The effect of HIV in a general population cohort in Malawi. AIDS 24: 417-426.

29. Guerra-Assuncao JA et al., 2015. Recurrence due to relapse or reinfection with Mycobacterium tuberculosis: a whole-genome sequencing approach in a large, population-based cohort with a high HIV infection prevalence and active follow-up. J Infect Dis 211:1154-1163.

30. Centers for Disease Control and Prevention, 2013. Core Curriculum on Tuberculosis: What the Clinician Should Know. Available at: https://www.cdc.gov/tb/education/corecurr/pdf/corecurr_all.pdf. Accessed February 24, 2019.

31. Espinal MA et al., 2001. Determinants of drug-resistant tuberculosis: analysis of 11 countries. Int J Tuberc Lung Dis 5: 887-893.

32. Yang Z, Kong Y, Wilson F, Foxman B, Fowler AH, Marrs CF, Cave MD, Bates JH, 2004. Identification of risk factors for extrapulmonary tuberculosis. Clin Infect Dis 38: 199-205.

33. Gonzalez OY, Adams G, Teeter LD, Bui TT, Musser JM, Graviss EA, 2003. Extra-pulmonary manifestations in a large metropolitan area with a low incidence of tuberculosis. Int $J$ Tuberc Lung Dis 7: 1178-1185.

34. Ohene SA, Bakker MI, Ojo J, Toonstra A, Awudi D, Klatser P, 2019. Extra-pulmonary tuberculosis: a retrospective study of patients in Accra, Ghana. PLoS One 14: e0209650.

35. Yang Z, Yang D, Kong Y, Zhang L, Marrs CF, Foxman B, Bates JH, Wilson F, Cave MD, 2005. Clinical relevance of Mycobacterium tuberculosis plcD gene mutations. Am J Respir Crit Care Med 171: 1436-1442.

36. Davis JL et al., 2014. Impact of GeneXpert MTB/RIF on patients and tuberculosis programs in a low-burden setting. A hypothetical trial. Am J Respir Critical Care Med 189: 1551-1559.

37. Chamie G, Luetkemeyer A, Walusimbi-Nanteza M, Okwera A, Whalen CC, Mugerwa RD, Havlir DV, Charlebois ED, 2010. Significant variation in presentation of pulmonary tuberculosis across a high resolution of CD4 strata. Int J Tuberc Lung Dis 14: 1295-1302.

38. Keiper MD, Beumont M, Elshami A, Langlotz CP, Miller WT, 1995. CD4 T lymphocyte count and the radiographic presentation of pulmonary tuberculosis: a study of the relationship between these factors in patients with human immunodeficiency virus infection. Chest 107: 74-80. 